\title{
Adherence to physical activity guidelines and functional fitness of elderly women, using objective measurement
}

\author{
Agnieszka Nawrocka', Władysław Mynarski', Jarosław Cholewa' \\ ${ }^{1}$ Department of Recreation, The Jerzy Kukuczka Academy of Physical Education in Katowice, Poland \\ Nawrocka A, Mynarski W, Cholewa J. Adherence to physical activity guidelines and functional fitness of elderly women, using objective \\ measurement. Ann Agric Environ Med. 2017; 24(4): 632-635. doi: 0.5604/12321966.1231388
}

\section{Abstract}

Introduction and objective. Physical activity is an important factor in maintaining the health and functional fitness of elderly people. The aim of the study was to determine the number of senior women meeting the physical activity guidelines, and their level of functional fitness in comparison to women who are not sufficiently physically active.

Materials and method. The study involved 61 women, aged 60-75. Physical activity was monitored on seven consecutive days of the week, using a triaxial accelerometer ActiGraph GT3X. Results of the assessment of physical activity were verified against the Global Recommendations of Physical Activity for Health. The Senior Fitness Test (Fullerton Test) was used to evaluate functional fitness.

Results. In the studied group, 36.1\% achieved the recommended level of physical activity. All those examined mainly undertook physical activity of low intensity. Vigorous physical activity during the week was noted in only 6 seniors. Women who met the recommendations of physical activity achieved significantly better results in test trials, e.g. Chair Stands, Up and Go, Six Minute Step Test.

Conclusions. Adherence to physical activity guidelines was associated with better functional fitness of older women. However, less than half of the examined seniors met the Global Recommendations on Physical Activity for Health.

Key words

energy expenditure, seniors, recommendations, actigraph Gt3X, Fullerton Test, accelerometry, senior fitness test

\section{INTRODUCTION}

The constant lengthening of average life expectancy is one of the main causes of global tendencies of elderly population growth in the demographic structure of society. However, the results of numerous studies show that the healthy life expectancy indicator is systematically decreasing $[1,2]$. The incidence of cardiovascular diseases and cancer which are the major cause of death is increasing. More and more people are overweight and obese. Functional fitness of seniors is worsening continually. These complaints are often interdependent and overlapping, resulting in serious social and economic consequences. This situation has contributed to the increased interest in lifestyle and its impact on the health and functional abilities of the elderly [3].

Regular physical activity (PA) is an important element of lifestyle. Numerous epidemiological studies have proved that it has positive influence on reducing mortality and the incidence of many diseases [4-6]. Regular physical activity also helps to maintain functional abilities which play a crucial role in self-reliance and motor resourcefulness in everyday life, contributing to having a positive self-esteem for the quality of life.

In order to determine the health-related level of physical efforts (specifying frequency, time and intensity) the Global Recommendations on Physical Activity for Health have been developed. At present, they are popularized by many world

Address for correspondence: Agnieszka Nawrocka, Department of Recreation, The Jerzy Kukuczka Academy of Physical Education in Katowice, Poland

E-mail:a.nawrocka@awf.katowice.pl

Received: 04 July 2014; accepted: 29 September 2014; first published on December, 2016 organizations and institutions [7]. It is recommended that elderly people should undertake physical activity of moderate intensity for at least 150 minutes weekly, or of high intensity for at least 75 minutes per week [1].

The performed study shows that the undertaking by the elderly of exercises of the recommended parameters significantly influences health and functional fitness. However, respondents were usually diagnosed by subjective methods (questionnaires) $[9,10,11]$. It has been proved many times that the accuracy of questionnaire research among seniors decreases with age $[12,13]$. It is therefore necessary to intensify research on the effects of physical activity of the elderly by using objective measurement methods.

\section{OBJECTIVE}

The aim of the research was to determine the percentage of elderly women who meet the Global Recommendations on Physical Activity for Health, and their level of functional fitness, compared to senior women not meeting the physical activity guidelines.

\section{MATERIALS AND METHOD}

In order to gather together the study group, the project was promoted in Senior Clubs and Universities of the Third Age. All volunteers who met the age criteria (at least 60 years of age) and agreed to take the full programme of research, showed a state of health which allowed them to undergo the test of functional fitness were qualified for the study. 
The full research programme was completed by 61 women, aged 60-75 years. The project was positively assessed by the Bio-Ethic Committee of the Jerzy Kukuczka Academy of Physical Education, in Katowice, Poland.

Physical activity was monitored for 7 consecutive days of the week by a triaxial accelerometer ActiGrpah GT3X, attached to the waist. This device records acceleration of the body: sagittally, frontally and laterally, and is equipped with an inclinometer which identifies changes in body position. On the basis of these parameters, weekly and daily energy expenditures were calculated in kilocalories (Kcal), as well as the number of steps performed by using the programme Actilife 5.0 Software. In order to compare the PA measurement results to those recommended by the WHO, intensity levels were set by undertaken physical activity. Cut points: 2,020-5,998 count/min for moderate intensity activity (MPA) and $>5,999$ count $/ \mathrm{min}$ for high intensity of activity (VPA) were taken [14].

Estimated parameters of physical activity (frequency, duration in one day and the intensity of effort) were interpreted on the basis of the PA guidelines, which allowed classification of each woman as sufficiently or insufficiently physically active. Senior women performing moderate physical effort (MPA) for at least 150 minutes per week, or intensive physical efforts (VPA) for at least 75 minutes per week, or an appropriate (tantamount) combination of the efforts of moderate and high intensity, were classified as sufficiently physically active.

Senior Fitness Test (SFT - Fullerton Test) for people over 60 years of age [15] was applied to assess functional performance. This test allows for assessment of strength and flexibility of lower and upper body, dynamic balance and aerobic endurance. The following trial tests were performed [15]:

1) 30-Second Chair Stand - to assess lower body strength. Number of full stands in 30 seconds with arms folded across he chest.

2) Arm Curl - to assess upper body strength. Number of full curls in 30 seconds holding a hand weight of $2 \mathrm{~kg}$.

3) Back Scratch - to assess upper body flexibility. With one hand reaching over the shoulder and the other hand in the middle of the back. The result of this trial was the number of centimeters between extended middle fingers (+ or -).

4) Chair Sit and Reach - to assess lower body flexibility. Test was performed in a sitting position in front of a chair, with one leg extended and hands reaching as far as possible toward toes. The result of this trial was the distance calculated in centimeters ( + or -) between extended fingers and tip of the toes.

5) 8-Foot Up and Go - to asses agility / dynamic balance. Number of seconds required to get up from the chair, walk 8 feet distance $(2.44 \mathrm{~m})$, turn and return to the seated position.

6) 6-Minute Walk - to assess aerobic endurance. The result of this test was distance in meters walked in 6 minutes around 40 meters course. This test was performed on a different day than the others. Immediately before and after completing the march, heart rate was measured by bulbar heart monitor, and the examined women evaluated the severity of subjective feeling of effort in a 20-point Borg scale.

These trials, except for the 6-minute walk, were performed twice, and the better results were selected for analyses.
Statistical Analysis. For all quantitative variables, basic parameters of descriptive statistics were calculated: arithmetic mean (Mean) and standard deviation (SD). In assessment of the intergroup, differentiation (criteria for age and level of PA) Kruskal-Wallis and Mann Whitney tests were used. Statistical analyses were performed on IBM SPSS. P-value was set at a $5 \%$ level of significance.

\section{RESULTS}

No significant variation of the basic parameters of somatic build in different age groups was found (Tab. 1). Average BMI values were slightly higher than those adopted by the WHO and indicated overweight in some examined women, which is typical for this age.

Table 1. Characteristics of somatic parameters in examined women acc. to age groups

\begin{tabular}{lcccccccc}
\hline & \multicolumn{7}{c}{ Age [years] } \\
\cline { 2 - 9 } & \multicolumn{1}{c}{$60-64(\mathrm{n}=24)$} & $65-69(\mathrm{n}=23)$ & $70-75(\mathrm{n}=14)$ & \multicolumn{2}{c}{ Total $(\mathrm{n}=61)$} \\
\cline { 2 - 9 } & Mean & SD & Mean & SD & Mean & SD & Mean & SD \\
\hline Age [years] & 61.83 & 1.40 & 66.87 & 1.42 & 72.43 & 1.70 & 66.16 & 4.36 \\
\hline Body Height [cm] & 160.79 & 5.15 & 158.96 & 4.69 & 159.57 & 3.03 & 159.82 & 4.57 \\
\hline Body Weight [kg] & 70.71 & 11.92 & 64.07 & 9.07 & 72.90 & 11.27 & 68.71 & 11.23 \\
\hline Body Fat [\%] & 35.83 & 7.14 & 34.25 & 4.82 & 38.55 & 7.78 & 35.86 & 6.62 \\
\hline BMI [kg/m²] & 27.62 & 4.47 & 26.58 & 2.85 & 28.63 & 4.26 & 27.08 & 4.01 \\
\hline${ }^{*} \mathrm{p}<0.05$ & & & & & & & &
\end{tabular}

Analysis of physical activity parameters monitored by accelerometer indicated a high dispersion of results (Tab. 2). Women performed most physical activity of low intensity $(<4 \mathrm{MET})$, while vigorous physical activity $(>6 \mathrm{MET})$ in the monitored week was observed only in 6 seniors $(9.8 \%)$. Interpretation of the level of physical activity parameters examined in relation to the physical activity guidelines, revealed that $36 \%$ of the women met the criteria for the Global Recommendations on Physical Activity for Health (Tab.2).

Table 2. Characteristics of physical activity parametersandthe percentage ofmeeting thePAguidelinesin examined women

\begin{tabular}{|c|c|c|c|c|c|c|c|c|}
\hline & \multirow{2}{*}{$\mathrm{N}$} & \multirow{2}{*}{$\%$} & \multirow{2}{*}{ Mean } & \multirow{2}{*}{ SD } & \multicolumn{2}{|c|}{ Meetcriteria } & \multicolumn{2}{|c|}{ Not meetcriteria } \\
\hline & & & & & $\mathrm{N}$ & $\%$ & $\mathrm{~N}$ & $\%$ \\
\hline WPA [kcal/week] & 61 & 100 & 2094.9 & 909.29 & & & & \\
\hline DPA [kcal/week] & 61 & 100 & 299.28 & 129.90 & & & & \\
\hline WNS [nr/week] & 61 & 100 & 50571 & 21689 & & & & \\
\hline DNS [nr/week] & 61 & 100 & 7224.4 & 3098.4 & & & & \\
\hline LPA [min/week] & 61 & 100 & 189.6 & 75.6 & & & & \\
\hline MPA [min/week] & 59 & 96.7 & 130.1 & 113.9 & & & & \\
\hline VPA [min/week] & 6 & 9.8 & 11.67 & 12.66 & & & & \\
\hline PA Guidelines & & & & & 22 & 36.1 & 39 & 63. \\
\hline
\end{tabular}

WPA - weekly physical activity; DPA - daily physical activity; WNS - weekly number of steps; DNS - daily number of steps; LPA - low physical activity; MPA - moderate physical activity; VPA - vigorous physical activity

The recommendations on physical activity for health include only moderate (MPA) and vigorous physical activity (VPA). Detailed analysis within these levels of physical activity showed that in women who did not meet the PA 
recommendations, the monitoring equipment did not register within a week any vigorous activity, and moderate activity was undertaken by an average of 60 minutes during the week (8.5 min/day) (Fig. 1).

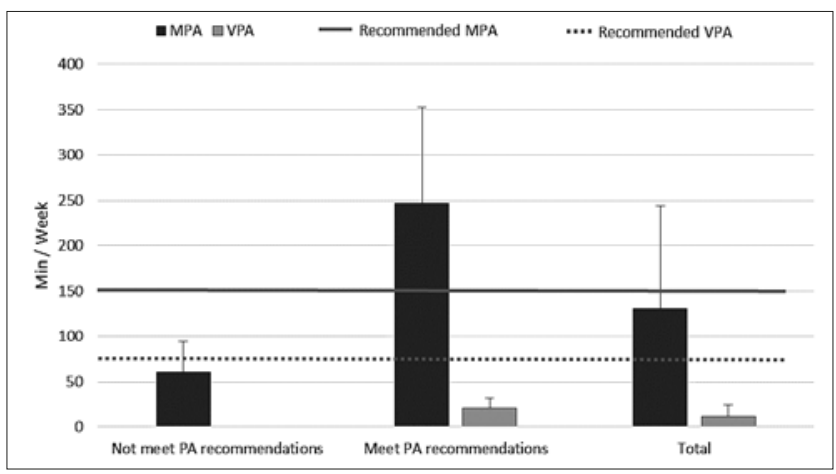

Figure 1. Weekly moderate and vigorous physical activity in women who met and those who did not meet physical activity enhancing criteria.

PA - physical activity; MPA - moderate physical activity; VPA - vigorous physical activity.

Senior women who met the recommendations of the Global Recommendations on Physical Activity for Health achieved better results in all the tests of functional fitness, assessed by the Senior Fitness Test (Tab. 3). However, statistical significance was found only in the tests: Getting up from a Chair (power unit efficiency evaluation of the lower limbs), Up and Go (assessing dynamic balance) and Six Minute Step Test (assessing aerobic endurance). Moreover, those examined who met the criteria of physical activity, compared to the insufficiently active women covered, on average, a longer distance in the 6-minute walk test and obtained a similar value of post-effort induced heart rate. These women also declared a significantly lower feeling of fatigue after the trial (Tab. 3).

Table 3. Differentiated level of functional fitness in women meeting and not meeting physical activity guidelines

\begin{tabular}{lccccc}
\hline & \multicolumn{5}{c}{ PA Recommendations } \\
\cline { 2 - 6 } & $\begin{array}{c}\text { Not meet criteria } \\
(\mathrm{n}=39)\end{array}$ & $\begin{array}{c}\text { Meet criteria } \\
(\mathrm{n}=22)\end{array}$ & \\
\cline { 2 - 6 } & Mean & SD & Mean & SD & $\mathrm{p}$ \\
\hline Chair Stand [nr of rep.] & 17.41 & 3.04 & 19.59 & 3.76 & $\mathbf{0 . 0 4 4}$ \\
Arm Curl [nr of rep.] & 22.10 & 4.01 & 22.86 & 3.04 & 0.587 \\
Chair Sit and Reach [cm +/-] & 4.82 & 9.89 & 8.09 & 7.22 & 0.157 \\
Up and Go [s] & 4.88 & 0.37 & 4.54 & 0.38 & $\mathbf{0 . 0 0 1}$ \\
BackScratch Test [cm +/-] & -2.04 & 6.28 & 0.07 & 5.22 & 0.410 \\
Six Minute Step Test - TM6: & & & & & \\
\multicolumn{1}{c}{ Distance [m] } & 508.85 & 44.93 & 556.27 & 43.97 & $\mathbf{0 . 0 0 0}$ \\
\multicolumn{1}{c}{ HeartRatebefore TM6 } & 70.03 & 7.21 & 67.77 & 5.72 & 0.351 \\
$\quad$ HeartRateafter TM6 & 120.87 & 10.56 & 121.59 & 8.26 & 0.792 \\
$\quad$ Borg Scale [pkt] & 12.54 & 1.14 & 11.82 & 1.01 & $\mathbf{0 . 0 1 8}$ \\
\hline
\end{tabular}

\section{DISCUSSION}

The study shows that more than one-third of senior women meet weekly health-enhancing physical activity recommendations. Analysis of world literature indicates that comparing the percentages of people engaging in health-enhancing physical activity is difficult due to the multiplicity of methods of assessment and recommendations (recommendations), according to which the results are interpreted. Sun and Norman [16], by making a meta-analysis during 2001-2011 concerning the implementation of the recommendations of physical activity by persons over 60 years of age, that the criteria for health-promoting interests ranged in extreme cases from $2.4-83 \%$.

Using objective measurements (accelerometer) of physical activity, the criterion of taking at least 150 minutes MVPA per week was met the $2.5 \%$ of people over the age of 65 in the UK [17]. Davis and Fox [18], based on the same recommendations, estimated that $\mathrm{PA}$ guidelines were met by $1.84 \%$ of senior citizens from France and Italy. Colley and Garriguet [19] found that the desired health physical activity was undertaken by $13.1 \%$ of seniors in Canada, including $12.6 \%$ of women aged $60-79$ years.

Different results were obtained by Hurtig-Wennlof and Hagstromer [20], who observed the recommended physical activity in up to $87 \%$ of seniors in Sweden; the research, however, concerned a much smaller group $(n=54)$ compared to other presented analyses in which the number of examined ranged from 200 - 900 seniors. Moreover, in all the abovequoted studies, different criteria were used to verify the activity of the various levels of intensity. Tucker and Welk [21], for the level of MVPA accepted values of $>2020$ counts/ min, while Harrisand Owen [17] >2,000 counts/min, Davis and Fox [18] >1,952 counts/min, Colley and Garriguet [19] $>1,535$ count/min, and Hurtig-Wennlof and Hagstromer [20] $>760$ count $/ \mathrm{min}$. The inclusion of such low value probably contributed to the high proportion of Swedish seniors meeting the criteria for health-enhancing physical activity. On the other hand, the results of the 'SHARE $50+$ in Europe' project carried out in 13 European countries, also indicated that the highest levels of MVPA were presented by seniors in Sweden and Switzerland. In the ranking, Poland was placed in the last place [22].

Despite the diversity of the PA assessment procedures listed in most studies conducted in large populations using accelerometers, the proportion of seniors meeting criteria for health-enhancing physical activity did not exceed an average of $15 \%$. The results of the presnted study, in which $36 \%$ of seniors met the Global Recommendations on Physical Activity for Health, can therefore be considered as optimistic. This may be due to the specific nature of the study group, whose participants were from institutions focused on various forms of activating seniors (Universities of the Third Age, Senior Clubs). On the other hand, participation in the study was voluntary, and the condition was to agree on implementing the full programme of tests, including tests of physical fitness. It can be assumed that some physically inactive women, with a low level of physical fitness, deliberately resigned from participation in the study.

The dependence between physical activity and functional fitness has also been the subject of many studies. Milanovic and Pantelic [23] pointed out the relationship of weekly physical activity with the results of all SFT tests, in particular, the 'Chair Stand', 'Arm Curl', and attempts to assess dynamic balance. Implementation of the PolSenior 6-month programme of recreation led to a significant improvement in all test results SFT [24]. In the current research, meeting physical activity guidelines also significantly differentiated 
the strength fitness level of the lower limbs, dynamic balance and efficiency assessed in a 6-minute walk. The beneficial effect of MVPA on the efficiency of older people, assessed by the Senior Fitness Test, was also shown by Santos Silva et al. [25]. The conclusion to be drawn are that even at an advanced age, the human body is sensitive to movement stimuli in the form of regular physical activity.

\section{CONCLUSIONS}

1. A little more than one-third of the examined seniors met the Global Recommendations on Physical Activity for Health.

2. A very low percentage of senior women undertook vigorous physical activity.

3. Meeting physical activity guidelines was associated with better functional fitness, which guarantees life self-reliance and independence for seniors.

Implication for further research: further research should be aimed at examining the effectiveness of motor programmes for activating seniors, based on diverse health-enhancing recommendations.

\section{REFERENCES}

1. Crimmins E, Beltrán-Sánchez H. Mortality and morbidity trends: is there compression of morbidity? J Gerontol B Psychol Sci Soc Sci. 2011; 66(1): 75-86. doi: 10.1093/geronb/gbq088.

2. Freeman K. U.S. lives: longer but sicker? Environ Health Perspect. 2011; 119(3): 1-2. doi: 10.1289/ehp.119-a118a.

3. Mynarski W, Rozpara M, Nawrocka A, Borek Z, Powerska A, Garbaciak W. Physical activity of middle-age adults aged 50-65 years in view of health recommendations. Eur Rev Aging Phys Act. 2014; 11; 141.

4. Cicero AF, D’Addato S, Santi F, Ferroni A, Borghi C, Brisighella Heart S. Leisure-time physical activity and cardiovascular disease mortality: the Brisighella Heart Study. J Cardiovasc Med (Hagerstown). 2012; 13(9): 559-64. doi: 10.2459/JCM.0b013e3283516798.

5. Chen LJ, Fox KR, Ku PW, Sun WJ, Chou P. Prospective associations between household-, work-, and leisure-based physical activity and allcause mortality among older taiwanese adults. Asia Pac J Public Health. 2012; 24(5): 795-805. Epub 2012/03/20. doi: 10.1177/1010539511404397.

6. Petersen CB, Gronbaek M, Helge JW, Thygesen LC, Schnohr P, Tolstrup JS. Changes in physical activity in leisure time and the risk of myocardial infarction, ischemic heart disease, and all-cause mortality. Eur J Epidemiol. 2012; 27(2): 91-9. doi: 10.1007/s10654-012-9656-Z.

7. Rahl RL. Physical activity and health guidelines: recommendations for various ages, fitness levels, and conditions from 57 authoritative sources. Human Kinetics. 2010.
8. WHO. Global Recommendations on Physical Activity for Health 2011:http://whqlibdoc.who.int/publications/2010/9789241599979_eng. pdf. (Access: 20.09.2013)

9. Brovold T, Skelton DA, Sylliaas H, Mowe M, Bergland A. Association between health-related quality of life, physical fitness, and physical activity in older adults recently discharged from hospital. J Aging Phys Act. 2014; 22(3): 405-13. doi: 10.1123/JAPA.2012-0315.

10. Gouveia ER, Maia JA, Beunen GP, Blimkie CJ, Fena EM, Freitas DL. Functional fitness and physical activity of Portuguese communityresiding older adults. J Aging Phys Act. 2013; 21(1): 1-19.

11. Bergier J. Aktywność fizyczna społeczeństwa - współczesny problem (przegląd badan). (Physical activity of the society - review of research). Human and Health. 2012; 6(1): 5-14 (in Polish).

12. Grimm EK, Swartz AM, Hart T, Miller NE, Strath SJ. Comparison of the IPAQ-Short Form and accelerometry predictions of physical activity in older adults. J Aging Phys Act. 2012; 20(1): 64-79. Epub 2011/12/23.

13. Tomioka K, Iwamoto J, Saeki K, Okamoto N. Reliability and validity of the International Physical Activity Questionnaire (IPAQ) in elderly adults: the Fujiwara-kyo Study. J Epidemiol. 2011; 21(6): 459-65.

14. Troiano RP, Berrigan D, Dodd KW, Masse LC, Tilert T, McDowell M. Physical activity in the United States measured by accelerometer. Med Sci Sports Exerc. 2008; 40(1): 181-8. doi: 10.1249/mss.0b013e31815a51b3.

15. Rikli RE, Jones CJ. Senior fitness test manual. Human Kinetics Publishers. 2001;1.

16. Sun F, Norman IJ, While AE. Physical activity in older people: a systematic review. BMC Public Health. 2013; 13: 449-66. doi: $10.1186 / 1471-2458-13-449$

17. Harris TJ, Owen CG, Victor CR, Adams R, Cook DG. What factors are associated with physical activity in older people, assessed objectively by accelerometry? Br J Sports Med. 2009; 43(6): 442-50. doi: 10.1136/ bjsm.2008.048033.

18. Davis MG, Fox KR. Physical activity patterns assessed by accelerometry in older people. Eur J Appl Physiol. 2007; 100(5): 581-9. doi: 10.1007/ s00421-006-0320-8

19. Colley RC, Garriguet D, Janssen I, Craig CL, Clarke J, Tremblay MS. Physical activity of Canadian adults: accelerometer results from the 2007 to 2009 Canadian Health Measures Survey. Health Rep. 2011; 22(1): 7-14.

20. Hurtig-Wennlof A, Hagstromer M, Olsson LA. The International Physical Activity Questionnaire modified for the elderly: aspects of validity and feasibility. Public Health Nutr. 2010; 13(11): 1847-54. doi: 10.1017/S1368980010000157.

21. Tucker JM, Welk GJ, Beyler NK. Physical activity in U.S.: adults compliance with the Physical Activity Guidelines for Americans. Am J Prev Med. 2011; 40(4): 454-61. doi: 10.1016/j.amepre.2010.12.016.

22. Myck M. Aktywność fizyczna populacji 50+ w Europie. 2009 Contract No.: CenEA Research Note Series RN03pl/09

23. Milanovic Z, Pantelic S, Trajkovic N, Sporis G, Kostic R, James N. Age-related decrease in physical activity and functional fitness among elderly men and women. Clin Interv Aging. 2013; 8: 549-56. doi: 10.2147/CIA.S44112.

24. Rowiński R, Dąbrowski A. Rekreacja fizyczna a sprawność funkcjonalna i jakość życia osób starszych. In: Mossakowska M, Więcek A, Błędowski $\mathrm{P}$, editors. Aspekty medyczne, psychologiczne, socjologiczne i ekonomiczne starzenia się ludzi w Polsce. Poznań Termedia; 2012. p. 45-52 (in Polish).

25. Santos DA, Silva AM, Baptista F, Santos R, Vale S, Mota J, et al. Sedentary behavior and physical activity are independently related to functional fitness in older adults. Experimental Gerontology. 2012; 47(12): 908-12. doi: 10.1016/j.exger.2012.07.011. 